\title{
Nrf-2 and H0-1 Expression in Medulloblastoma: A Clinicopathological Analysis
}

\author{
Li Tang1, Yu Deng2, Minna Gao², Xiao Lin'², Jin Zhu², Yu Li² \\ ${ }^{1}$ Department of Pathophysiology, Chongqing Medical University, Chongqing, China \\ ${ }^{2}$ Department of Pathology, Institute of Neuroscience, Chongqing Medical University, Chongqing, China \\ Email: tanglicq@126.com, liyu100@163.com
}

How to cite this paper: Tang, L., Deng, Y., Gao, M.N., Lin, X., Zhu, J. and Li, Y. (2017) Nrf-2 and HO-1 Expression in Medulloblastoma: A Clinicopathological Analysis. Journal of Biosciences and Medicines, 5, 142-147.

https://doi.org/10.4236/jbm.2017.53015

Received: March 6, 2017

Accepted: March 31, 2017

Published: April 3, 2017

\begin{abstract}
Medulloblastoma (MB) is one of the most common malignant tumors with poor survival in children. Nuclear factor erythroid 2-related factor2 (Nrf-2) and heme oxygenase-1 (HO-1) have been considered to play major roles in the pathogenesis of many tumors. There is no report about clinicopathological significance of Nrf-2 and HO-1 expression in medulloblastoma. In the present study, to explore the expression and potential function of Nrf-2 and HO-1 in $\mathrm{MBs}$, immunohistochemistry was used to examine the Nrf-2 and HO-1 expression in $41 \mathrm{MBs}$ and 27 control tissues adjacent to the tumor. The results showed that in the cases of $\mathrm{MB}$, the positive expression rates of Nrf-2 and HO-1 (82.9\% and 78.0\%) were significantly increased compared with that (37.0\% and $29.6 \%$ ) in peritumoral control brain tissues. The difference was statistically significant $(P<0.001)$. A positive correlation between the expression of Nrf-2 and HO- 1 in $\mathrm{MB}(\mathrm{r}=0.542, P<0.05)$ was observed. However, there was no definite correlation among the expression of Nrf-2 and HO-1 and the clinical pathological features $(P>0.05)$. The abnormal expression of Nrf-2 and HO-1 in $\mathrm{MB}$ suggest that the Nrf-2/HO-1 pathway plays an important role in the formation and development of $\mathrm{MB}$ and may be a potential therapeutic target for $\mathrm{MB}$.
\end{abstract}

\section{Keywords}

Medulloblastoma, Nrf-2, HO-1, Immunohistochemistry

\section{Introduction}

Medulloblastomas (MB) is one of the most common malignant central nervous system (CNS) tumors in children [1] [2]. Researches find that MB originated from cerebellum. The cells have high mitotic activity and ability to spread throughout the CNS, and the poor survival rates is partly due to the lack of effective treatment. Evidence has accumulated that oxidative stress and inflamma- 
tion are closely related to the process of tumor formation and cell proliferation. The current studies found that the antioxidant and anti-inflammatory effects of many drugs occurred through activation of the nuclear factor erythroid2-related factor 2 (Nrf-2)/heme oxygenase-1 (HO-1) pathway. In this study, Nrf-2 and HO-1 expression levels were studied in $41 \mathrm{MB}$ and 27 control brain tissue adjacent to the tumor by immunohistochemistry. The correlations and clinicopathological factors were investigated to clarify the potential target for MB treatment.

\section{Materials and Methods}

\subsection{Patients and Tissues}

Medulloblastoma tissue samples from 41 patients and control brain tissue samples from 27 tissues adjacent to the tumor were diagnosed between September 2005 and December 2010 at the Department of Pathology in Chongqing Medical University. The diagnoses of MB were based on a combination of clinical information, morphologic examination and immunohistochemical results.

\subsection{Immunohistochemistry}

Nrf-2 and HO-1 expression were analyzed by immunohistochemistry.

Antigen retrieval was carried out by steaming $\left(20\right.$ minutes at $\left.80^{\circ} \mathrm{C}\right)$ in citrate buffer at $\mathrm{pH}$ 6.0. The following primary antibodies were used: a polyclonal anti-Nrf-2 antibody (Santa Cruz Biotechnology, CA, USA), diluted 1:200; a polyclonal anti-HO-1 antibody (Santa Cruz Biotechnology, CA, USA), diluted 1:100. Antigen visualisation was achieved by applying a standard streptavidin-perosidase (S-P) method, with diaminobenzidine as the chromogen. Sections treated without primary antibodies served as negative controls.

\subsection{Assessment of Immunoreactivity}

The positive reaction was defined as discrete localization of thechromogen in the cytoplasm and nuclear of all slices. The intensity of cytoplasmic and nucleic reaction were graded as negative (-, positive cells percentage bellow 5\%), mild positive $(+$, positive cells percentage is $6 \%-25 \%)$, moderate positive $(++$, positive cells percentage is $26 \%-50 \%)$ and strong positive $(+++$, positive cells are above $51 \%)$.

\subsection{Statistical Analysis}

The statistical analyses were performed using SPSS 16.0 (SPSS Inc., Chicago, IL, USA). The parametric variables were analyzed by using spearman rank correlation analysis. $P<0.05$ was regarded statistically significant.

\section{Results}

\subsection{Immunohistochemical Expression of $\mathrm{Nrf-2}$ and HO-1 in MB and Control Brain Tissue}

We employed immunohistochemistry to evaluate the expression of Nrf-2 and 
HO-1 in MB and normal brain tissues. The results of the immunohistochemical staining of Nrf-2 and HO-1 are summarized in Table 1 and illustrated in Figure 1.

\subsection{Relationship between the Expression of Nrf-2 and $\mathrm{HO}-1$ in $\mathrm{MB}$}

The relationship between expression of Nrf-2 and HO-1 are shown in Table 2, and the expression of $\mathrm{Nrf}-2$ is positively correlated to the expression of $\mathrm{HO}-1(\mathrm{r}=$ $0.542, p<0.05)$.

\subsection{Relationship of Nrf-2 and HO-1 Expression with Clinicopathological Features of MB}

The clinicopathological findings are summarized in Table 3. For the 41 patients, the median age was 15 years (range 1 - 56 years), and 29 patients $(70.7 \%)$ were younger than 15 years old. The tumor sizes were less than $1.5 \mathrm{~cm}$ in $80.5 \%(33 / 41)$ patients. $65.6 \%(27 / 41)$ patients were taken chemotherapy. There was also no significant association of Nrf-2 and $\mathrm{HO}-1$ expression with the clinical features of MB.

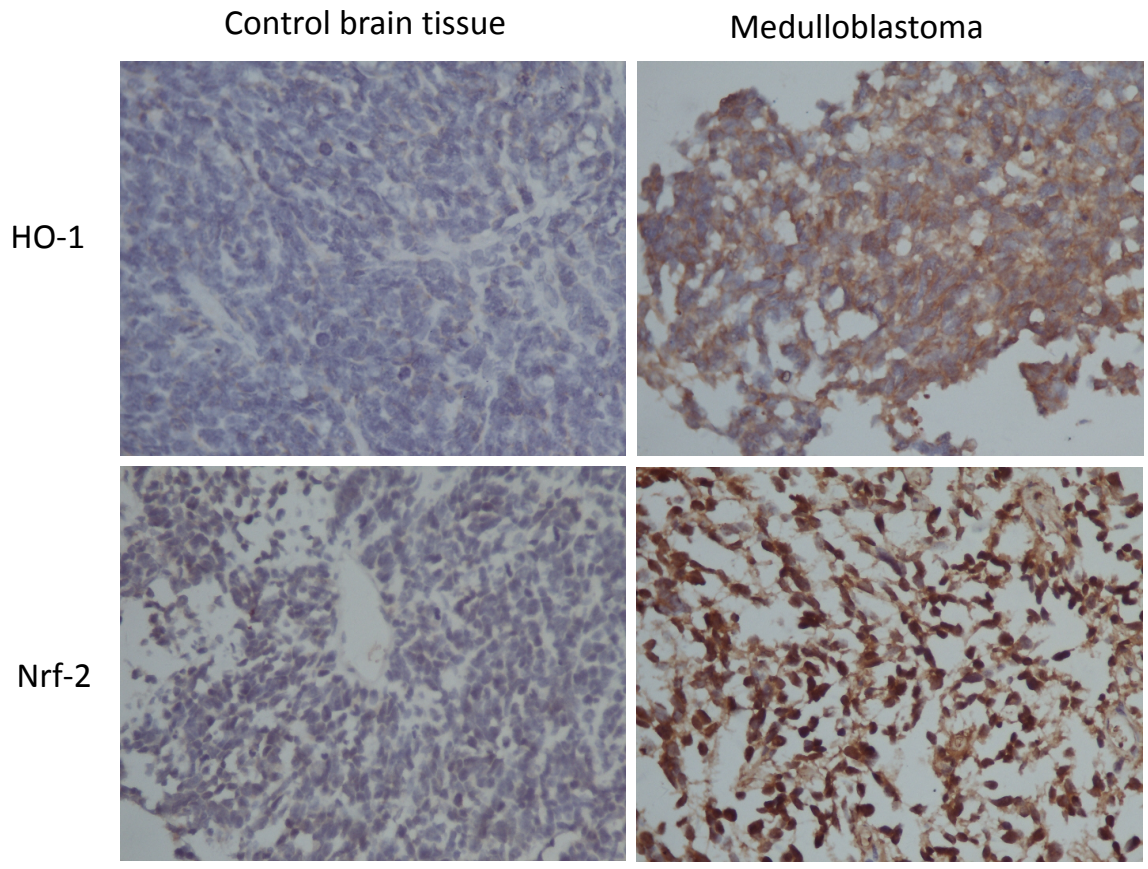

Figure 1. Expression of Nrf-2 and HO-1 in MB and control brain tissue $(\times 400)$.

Table 1. Expression of Nrf-2 and HO-1 in MB and control brain tissue.

\begin{tabular}{ccccc}
\hline \multirow{2}{*}{ Group } & \multicolumn{3}{c}{ Nrf-2 } & \multicolumn{3}{c}{ HO-1 } \\
\cline { 2 - 5 } & + & - & + & + \\
\hline Medulloblastoma & 34 & 7 & 32 & 9 \\
Normal brain tissue & 10 & 17 & 8 & 19 \\
Total & 44 & 24 & 40 & 28 \\
\hline
\end{tabular}


Table 2. The relationship between expression of Nrf-2 and HO-1 in MB.

\begin{tabular}{|c|c|c|c|}
\hline \multirow{2}{*}{ HO- 1} & \multicolumn{2}{|c|}{ Nrf-2 } & \multirow{2}{*}{ Total } \\
\hline & + & - & \\
\hline+ & 30 & 2 & 32 \\
\hline- & 4 & 5 & 9 \\
\hline Total & 34 & 7 & 41 \\
\hline
\end{tabular}

Table 3. Relationship of Nrf-2 and HO-1 expression with clinicopathological features of MB.

\begin{tabular}{|c|c|c|c|c|c|c|c|c|c|c|}
\hline & & \multirow{2}{*}{ Number (\%) } & \multicolumn{3}{|c|}{ Nrf-2 } & \multirow{2}{*}{$\mathrm{P}$} & \multicolumn{3}{|c|}{ HO-1 } & \multirow{2}{*}{$\mathrm{P}$} \\
\hline & & & + & ++ & +++ & & + & ++ & +++ & \\
\hline \multirow[t]{2}{*}{ Gender } & Male & $23(56.1)$ & 13 & 6 & 2 & \multirow{2}{*}{0.625} & 13 & 2 & 2 & \multirow{2}{*}{0.31} \\
\hline & Female & $18(43.9)$ & 8 & 4 & 1 & & 10 & 5 & 0 & \\
\hline \multirow[t]{2}{*}{ Age } & $\leq 16$ years & $29(70.7)$ & 15 & 5 & 3 & \multirow{2}{*}{0.434} & 16 & 6 & 1 & \multirow{2}{*}{0.497} \\
\hline & $>16$ years & $12(29.3)$ & 6 & 5 & 0 & & 7 & 1 & 1 & \\
\hline \multirow[t]{2}{*}{ Tumor size } & $\leq 1.5 \mathrm{~cm}$ & $33(80.5)$ & 17 & 8 & 1 & \multirow{2}{*}{0.484} & 18 & 5 & 1 & \multirow{2}{*}{0.625} \\
\hline & $>1.5 \mathrm{~cm}$ & $8(19.5)$ & 4 & 2 & 2 & & 5 & 2 & 1 & \\
\hline \multirow[t]{4}{*}{$\begin{array}{l}\text { Histological } \\
\text { type }\end{array}$} & Classical & $23(56.1)$ & 12 & 5 & 2 & & 13 & 4 & 2 & \multirow{4}{*}{1.000} \\
\hline & Desmoplastic/nodular & $14(34.1)$ & 7 & 3 & 1 & \multirow[b]{2}{*}{0.230} & 8 & 2 & 0 & \\
\hline & $\begin{array}{l}\text { With extensive } \\
\text { nodularity }\end{array}$ & $3(7.3)$ & 2 & 1 & 0 & & 1 & 1 & 0 & \\
\hline & Large cell/Anaplastic & $1(2.5)$ & 0 & 1 & 0 & & 1 & 0 & 0 & \\
\hline
\end{tabular}

\section{Discussion}

A growing body of evidence indicates that oxidative stress is responsible for the development of chronic diseases, such as cancer, diabetes, atherosclerosis, neurodegeneration, and aging [1] [2].

Nrf-2 is a member of transcription factor and plays a critical coordinator as regulating the redox balance and protecting cells against oxidative and inflammatory lesions. Nrf-2 exerts its balancing effects through regulating the expression of detoxification enzymes and antioxidant proteins to protect the body. Studies have suggested that induction of Nrf-2 can ameliorate neurodegeneration [3] [4]. An increased nuclear staining of Nrf-2 was found in surviving neurons of postmortem Parkinson's disease (PD) patients. Immunohistochemical analysis of Nrf-2 in tumor specimens of 60 patients with stage IIIB or IV non-small-cell lung cancer found that Nrf-2 positive staining was in nearly all cases [5]. Several researches showed the Nrf-2 activity is clearly connected with oncogenic kinase pathways, structural proteins, hormonal regulation, other transcription factors, and epigenetic enzymes involved in the pathogenesis of tumors [6]. In many human cancers, constitutive activation of Nrf- 2 caused elevated expression of Nrf- 2 target genes confers advantages in terms of stress resistance and cell proliferation in normal and cancer cells. 
HO-1 is one of the rate-limiting enzymes of the heme oxygenase, it breaks down heme to liberate biliverdin (a powerful antioxidant), ferrous iron $\left(\mathrm{Fe}^{2+}\right.$ ) and carbon monoxide (CO). HO-1 expression increased in stress and also constitutively active in many tumor types [7] [8]. Tumor growth often requires HO-1, and experimental down-regulation of HO-1 inhibited growth of various cancer types as well as increasing their sensitivity to radiotherapy and chemotherapy [9] [10]. There have been no published reports on expression of Nrf-2 and HO-1 in medulloblastoma. In our study, immunohistochemical analysis of Nrf-2 and HO-1 in medulloblastoma specimens of 41 patients was combined with clinicopathological features. The positive staining of Nrf-2 and HO-1 $(82.9 \%$ and $78.0 \%)$ in $\mathrm{MB}$ was obviously higher than that $(37.0 \%$ and $29.6 \%)$ in control tissues adjacent to the tumor, and the expression of Nrf-2 is positively correlated to the expression of HO-1 $(r=0.542, p<0.05)$. But there was no significant difference between the expression of Nrf-2 and HO-1 and the clinical features of the patients. These results are similar with the studies in many other malignant tumor and might provide the potentiality of putative biomarkers and therapeutic targets. The mechanisms and regulators for the expression of Nrf-2 and HO-1 need to be further studied.

\section{References}

[1] El-Sheikh, A., Fan, R., Birks, D., et al. (2010) Inhibition of Aurora Kinase A Enhances Chemosensitivity of Medulloblastoma Cell Lines. Pediatr Blood Cancer, 55, 35-41.

[2] Raso, A., Mascelfi, S., Biassoni, R., et a1. (2011) High Levels of PROM 1(CD133) Transcript Are a Potential Predictor of Poor Prognosis in Medulloblastoma. Neuro Oncol, 13, 500-508. https://doi.org/10.1093/neuonc/nor022

[3] Joshi, G. and Johnson, J.A. (2012) The Nrf2-ARE Pathway: A Valuable Therapeutic Target for the Treatment of Neurodegenerative Diseases. Recent Pat CNS Drug Discov., 7, 218-229. https://doi.org/10.2174/157488912803252023

[4] Gan, L. and Johnson, J.A. (2014) Oxidative Damage and the Nrf2-ARE Pathway in Neurodegenerative Diseases. Biochim Biophys Acta., 1842, 1208-1218. https://doi.org/10.1016/j.bbadis.2013.12.011

[5] Yang, H., Wang, W., Zhang, Y., et al. (2011) The Role of NF-E2-Related Factor 2 in Predicting Chemoresistance and Prognosis in Advanced Non-Small-Cell Lung Cancer. Clin Lung Cancer, 12, 166-171. https://doi.org/10.1016/j.cllc.2011.03.012

[6] Taguchi, K., Motohashi, H. and Yamamoto, M. (2011) Molecular Mechanisms of the Keap1-Nrf2 Pathway in Stress Response and Cancer Evolution. Genes to Cells, 16, 123-140. https://doi.org/10.1111/j.1365-2443.2010.01473.x

[7] Chi, P.L., Liu, C.J., Lee, I.T., et al. (2014) HO-1 Induction by CO-RM2 Attenuates TNF- $\alpha$-Induced Cytosolic Phospholipase A2 Expression via Inhibition of $\mathrm{PKC} \alpha$ Dependent NADPH Oxidase/ROS and NF- $\kappa$ B. Mediators Inflamm., 2014, 279171. https://doi.org/10.1155/2014/279171

[8] Jozkowicz, A., Was, H. and Dulak, J. (2007) Heme Oxygenase-1 in Tumors: Is It a False Friend? Antioxid Redox Signal, 9, 2099-2117.

https://doi.org/10.1089/ars.2007.1659

[9] Fang, J., Akaike, T. and Maeda, H. (2004) Antiapoptotic Role of Heme Oxygenase (HO) and the Potential of $\mathrm{HO}$ as a Target in Anticancer Treatment. Apoptosis, 9. 
27-35. https://doi.org/10.1023/B:APPT.0000012119.83734.4e

[10] Kinobe, R.T., Dercho, R.A. and Nakatsu, K. (2008) Inhibitors of the Heme Oxygenase-Carbon Monoxide System: On the Doorstep of the Clinic? Can J Physiol Pharmacol., 86, 577-599. https://doi.org/10.1139/Y08-066

Submit or recommend next manuscript to SCIRP and we will provide best service for you:

Accepting pre-submission inquiries through Email, Facebook, LinkedIn, Twitter, etc. A wide selection of journals (inclusive of 9 subjects, more than 200 journals)

Providing 24-hour high-quality service

User-friendly online submission system

Fair and swift peer-review system

Efficient typesetting and proofreading procedure

Display of the result of downloads and visits, as well as the number of cited articles Maximum dissemination of your research work

Submit your manuscript at: http://papersubmission.scirp.org/

Or contact jbm@scirp.org 